\title{
Enhancing Learning for Distance Students in an Undergraduate Engineering Course through Real-time Web-Conferencing
}

\section{Dr. John Matthew Long, Deakin University}

Dr. John M. Long completed his undergraduate degree in physics at the University of Michigan (Flint) in 1987, while working as an analytical chemist at AC Spark Plug, General Motors Corporation. In 1995 he completed a PhD in physics at Monash University in Melbourne, Australia. Since then he has worked in the School of Engineering at Deakin University, where he teaches physics, materials, and electronics.

\section{Mr. Simon William Cavenett, Deakin University}

Simon Cavenett is a Senior Lecturer and Director of Professional Practice (Engineering) at the School of Engineering at Deakin University. Prior to joining Deakin University in 2007 his 20 year career was based in industry. His career includes a number of significant achievements both in Australia and internationally, particularly involving the design and implementation of leading edge telecommunications and IT technologies. Simon has extensive experience internationally; having worked professionally based the United States for over 11 years prior to returning to Australia to join Deakin University.

\section{Ms. Eloise Gordon, Deakin University \\ Dr. Matthew Joordens, Deakin University}

Matthew A. Joordens (Member -IEEE, Fellow - The Institution of Engineers Australia, Mensa member) began his career with Industrial Control Technology designing control systems to automate various different industrial processes. For 5 years he designed microprocessor based control systems for companies such as Ford, Pilkington Glass, Webtek and Blue Circle Southern Cement. He then moved to Deakin University and wrote their first electronics units. Using his industrial experience he designed one of the first Australian Engineering degrees in Mechatronics that still runs at Deakin. He currently lectures units in Digital electronics, Microcontrollers, Robotics and Artificial Intelligence. His research areas are in Engineering Education and Robotics. 


\title{
Enhancing Learning for Distance Students in an Undergraduate Engineering Course through Real-time Web-Conferencing
}

\begin{abstract}
On-line education in engineering has attracted a great deal of interest in recent years. One of the difficulties faced in an on-line engineering program is how to ensure effective communication between lecturers and students, and among the students themselves. Techniques common ten years ago such as email, lecture notes posted to websites, and telephone conversations, are now seen as archaic when compared with opportunities offered by more modern communication technologies, such as real-time web-conferencing.

We present our efforts to use the web-conferencing software Elluminate-Live! for delivering tutorials, discussion classes, and even laboratory practicals to groups of students studying engineering off-campus, including students posted overseas. Examples are given from two disciplines. We then compare student feedback across all engineering subjects over the years 2012-2013. Our results show that students welcome web-conferencing as a very effective means to deliver classes to distance students and improve their learning experience.
\end{abstract}

\section{introduction}

In recent years there has been an increasing interest in delivering engineering courses through non-traditional means, such as by distance, on-line, flexible, and combinations/blends of located and on-line learning environments. ${ }^{1}$ On-line learning (also known as distance education) is now an accepted means by which tertiary education can be delivered to nontraditional students, who for many reasons are unable to attend regular on-campus classes. ${ }^{2}$ An increasing number of engineering schools are trialling on-line learning as a means to reach more students outside of traditional cohorts. ${ }^{3-5}$ For many years, Deakin University in Australia has delivered a fully-accredited undergraduate engineering program in both on-campus, offcampus, and blended modes, with majors that include mechanical, electrical, mechatronics, and civil engineering. ${ }^{6}$

Many of our on-line students live interstate or even overseas from the main campus. While the majority of our students reside within Australia, there is a significant number who reside outside Australia during the time of their enrolment. Some are Australians who are posted overseas, and some are international students studying through Deakin or through an international partnership. We have direct experience of teaching students who, at the time of their enrolment, reside in overseas countries, including

- New Zealand

- Malaysia

- Singapore

- Hong Kong

- Indonesia
- Saudi Arabia

- South Africa

- the United Kingdom

- the Netherlands
- $\quad$ the United Arab Emirates

- Mongolia

- Canada

- the United States. 
We even have taught handful of students while they were at sea, either in the merchant marine or in the Royal Australian Navy.

In our experience, isolation, lack of real-time contact with teaching staff, and lack of access to laboratories are some of the most significant challenges faced by these students, leading to high drop-out rates among on-line students. ${ }^{7}$ Educational challenges faced by their lecturers include difficulty teaching teamwork skills, ensuring effective group work among students, implementing cooperative and peer-based learning, supervising projects, and enabling the students to give in-class presentations. Laboratory work is also an issue, as some students are unable to attend on-campus lab classes because they live too far away from the main campus. Prior to 2006, primary communication between the lecturer and the students was by means of a course website or learning-management system. ${ }^{8}$ The course syllabus, assignments, lecture notes, problem solutions, and announcements would be posted on-line for the students to download in their own time. Communication between students was mainly by email or by means of on-line noticeboard/communications forum attached to the course website. Individual communication between students and lecturers was by email or telephone. For cooperative or group work, students would be put into on-line groups and would use on-line discussion forums for meetings. Students would make presentation on projects by means of a video recording made at home or in the workplace. Except for using telephones and on-line chat forums, most of the communication was asynchronous. There was limited communication among students and lecturers in a real-time format.

Since 2006, our on-line students have been required to attend yearly on-campus residential schools to better experience the "social" aspects of their engineering education. ${ }^{9}$ This includes performing practicals, attending functions with other students, and giving project presentations. This has improved the social interaction and communication in the class, but it is limited to two specific weeks per year. Most participants are required to take time off work to attend. Some students travel interstate, and thus require paid accommodation, which increases the cost of their education.

More modern communication technologies are making significant contributions towards alleviating these problems. Web-conferencing tools may be a means whereby tutorials or small class sessions can be delivered efficiently and in real time to groups of off-campus students. Numerous software packages exist, such as WebEx, Skype, Adobe Connect Pro, and Elluminate. Our initial work indicates that the Elluminate package may be an effective means to provide key aspects of the educational experience to on-line students. ${ }^{10,11}$

Educational institutions are beginning to use the Elluminate-Live! (E-live) $)^{12}$ software package to improve communication between lecturers and students. ${ }^{13,14}$ A session is booked by the lecturer for a specific time. The software produces a unique web address that is distributed to students in the class. Once the session begins, the presenter and students have access to an online whiteboard, real-time voice, video, and text transmission, and a number of single-click indicators that students can use to simulate actions in a classroom, such as raising one's hand, answering yes or no, and being in agreement or disagreement (figure 1). A list of students logged into the session is always visible. The lecturer has the ability to directly share with the 
students another program running on his computer, allowing real-time software demonstrations and data analysis. The session can also be recorded for viewing later. The software is run via a standard web browser and Java.

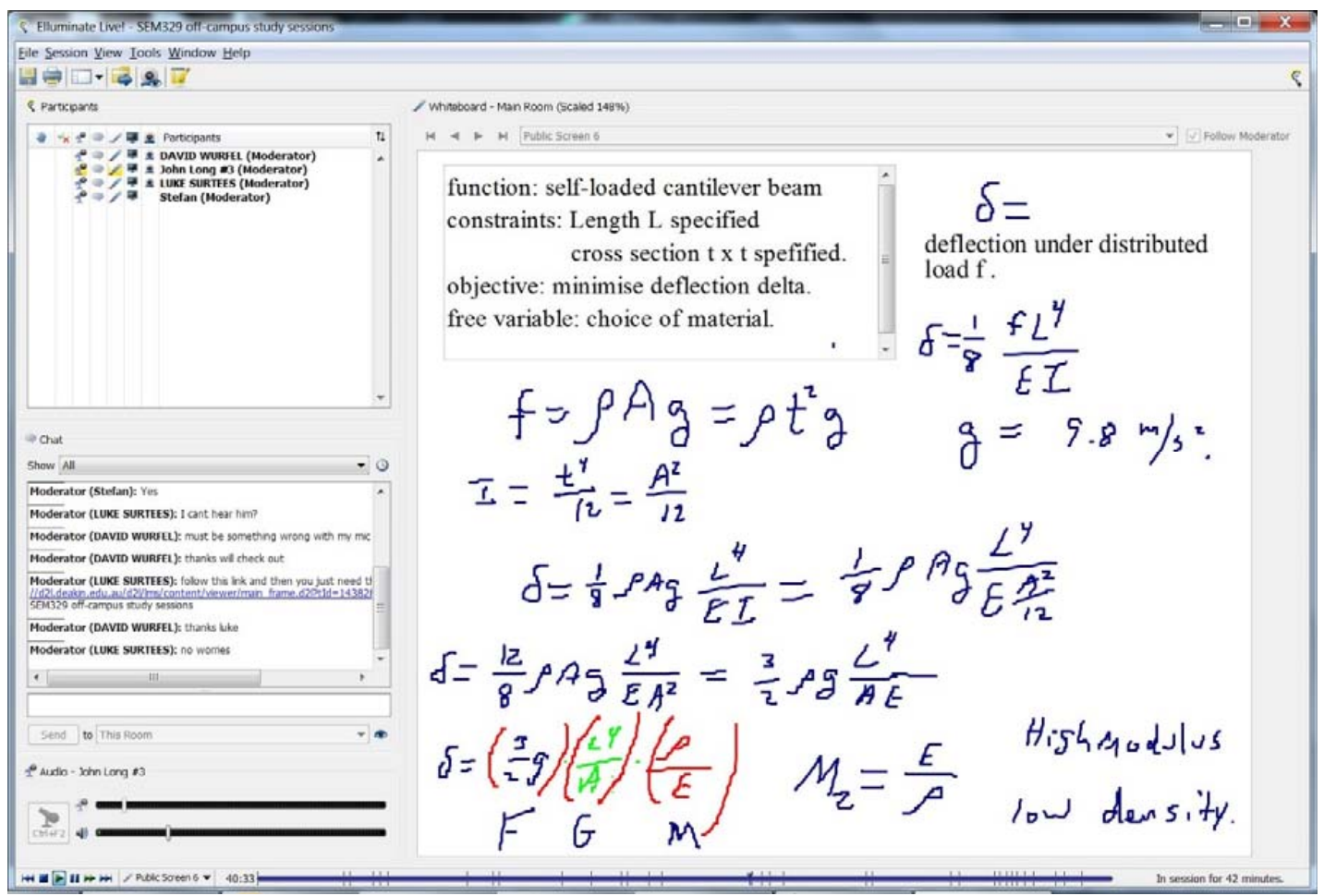

Figure 1: Screen-shot of E-live being used in a tutorial in a third-year mechanicalengineering and materials-selection class, showing the software's basic features.

\section{method}

E-live web-based tutorials were introduced in our school in 2009, first in mechanicalengineering and materials subjects. The application was mainly practicing problem-solving with a small group of on-line students. The following year tutorials in first-year physics began. The practice extended course-by-course over the following years. By semester-two 2013 all subjects in engineering used E-live to deliver tutorials to on-line students. We present here two examples of its implementation, taken from a management subject and a civil-engineering subject.

\section{third-year project management.}

Students studying project management in the third year of our four-year major are required to develop basic competency in using common computer-based productivity tools deployed in contemporary project management. Specifically the students are required to learn how to use the commercial off-the-shelf software application Microsoft Project to understand and apply the project-management theory learned in the relevant undergraduate subject and to develop a working knowledge of how such project management tools can be used.

The majority of our undergraduate engineering students have little or no knowledge of the Microsoft-Project software. As is common with effective learning methods for developing 
proficiency in using specific software applications, the teaching method for developing sufficient basic competency with this software centers on multiple hands-on assessed tasks conducted over multiple classes that seek to develop and reinforce students' understanding and ability through supported personal experience.

For our on-campus students this is achieved through the tradional tutorial class method with each student having access to a dedicated computer workstation during the class and thus able to personally use the Project application to work on assigned tasks. In these tutorial classes an experienced tutor provides guidance, advice, and support in the class as students undertake the tasks. For our on-line students, the teaching method options include requiring the students to attend specific tutorial classes at the campus, or other designated location, to replicate the inperson tutorial classes provided for on-campus enrolled students; requiring the students to learn how to use the software in their own time at their own preferred location using their own resources with remote tutoring support; or exploiting web-conferencing and online collaboration enabling software such as E-live to provide a real-time virtual classroom to replicate many of the salient qualities of live "in-person" tutorials conducted on campus. These salient qualities which E-live enables to be provided in the virtual classroom include the ability to disply an image, document, or software user interface window so that it is visible to the entire class; the ability for all participants to communicate with directly with each other, among a subset of participants, and with all participants; and the ability for students to be using a software application installed locally on their personal workstation while simultaneously observing what is being displayed to the entire class and what is being communicated to the entire class.

Recording the E-live tutorial sessions also provides all students, not only the on-line ones, with a recorded audiovisual class-based tutorial enhance their own-time learning and/or to enable students to catch up with live tutorial classes they may have been unable to attend on-campus or on-line. This ability to provide all students with a recording of a "real" tutorial class conducted with a group of fellow students has been found to be a desirable benefit when teaching specialised software applications such as Microsoft Project in which students typically have little or no skills or knowledge beforehand.

Figure 2 provides a screen-shot of an actual E-live tutorial session, conducted in August 2013, where students were being guided through some basic operations in Microsoft Project Profesional 2010. The typical setup for these on-line tutorials is evident - with most of the web browser window (the right box) dedicated to displaying the Project software application as seen and manipulated on the tutor's computer, a list of the virtual classroom's participants and their respective status (the upper left box), and a text-based chat stream visible to all participants (the lower left box). With access to the virtual classroom provided to all participants in a web-browser window, the flexibility for students to also be using the tutored software at the same time was provided. This is a significant advantage over pre-recorded teaching videos intended to provide the same learning outcomes. The recordings also enabled students, if they desired, to replay the tutorial session alongside their own use of the software application with an ability to pause, rewind, and fact forward the recording as desired.

\section{third-year civil engineering.}

The E-live software package is employed to deliver regular tutorials to on-line students across a number of third-year civil engineering subjects. A number of these focus on technical content, 
including structural analysis and design methods which regularly use formulas and hand-drawn sketches. Traditional face-to-face tutorials are particularly valuable to students in these courses, since the sessions facilitate demonstration and real-time interactions between the student and instructor. It was recognised that our on-line students were finding these subjects particularly challenging since they could not attend these face-to-face sessions.

The implementation of E-live tutorials enabled our on-line students to experience live demonstrations of problem solutions, allowing them to be involved in the solution process in a similar way to the face-to-face tutorial. Students are able to contribute to the solution, stop the instructor for clarification and talk with other students about the solution process, thereby enriching the learning experience and making it a far more active experience. Anecdotally, this has proven to be of real value to our distance students, who have previously been limited to passively watching a calculation demonstration via video (at best).

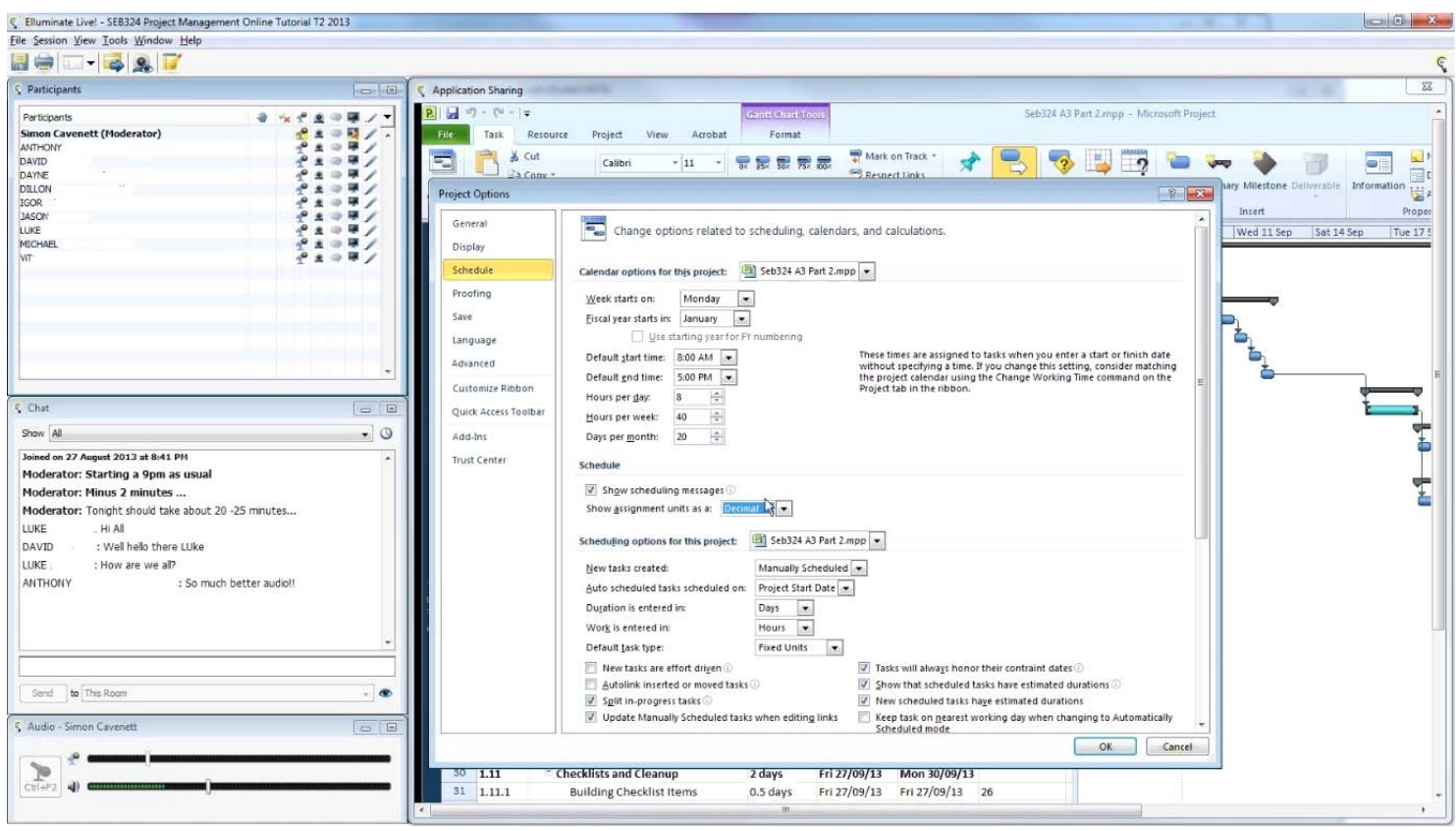

Figure 2: Screen-shot of E-live being used in a project-management tutorial.

The session is demonstrating the software package Microsoft Project.

Many of the E-live tutorials in third-year civil engineering consist of a number of elements, including a short slideshow presentation, open-floor discussion and live problem solutions. The instructor typically creates and shares the live solutions on a shared screen using a tablet PC and Microsoft OneNote software, as illustrated in the excerpt of tutorials shown in figure 3. The presentation component is created in Microsoft Powerpoint and uploaded to the E-live "room" before the session. Sharing of desktops allows participants to share live-feed information from other sources too, such as from the Internet and from design programs.

\section{multimode learning}

Web-based tutorials have enabled the simultaneous support of synchronous and asynchronous learning modes ${ }^{15}$ for all students studying engineering subjects with the efficiency of utilising 
the same tutorial sessions enabled by the E-live software package. For most subjects the online tutorial sessions are recorded and these session recordings are made available to students to access and view as and when desired. Through the provision of on-line sessions accessible in real-time as they occur and as recordings it is possible to provide at least one learning mode (synchronous or asynchronous) to all students regardless of their global geographical location.

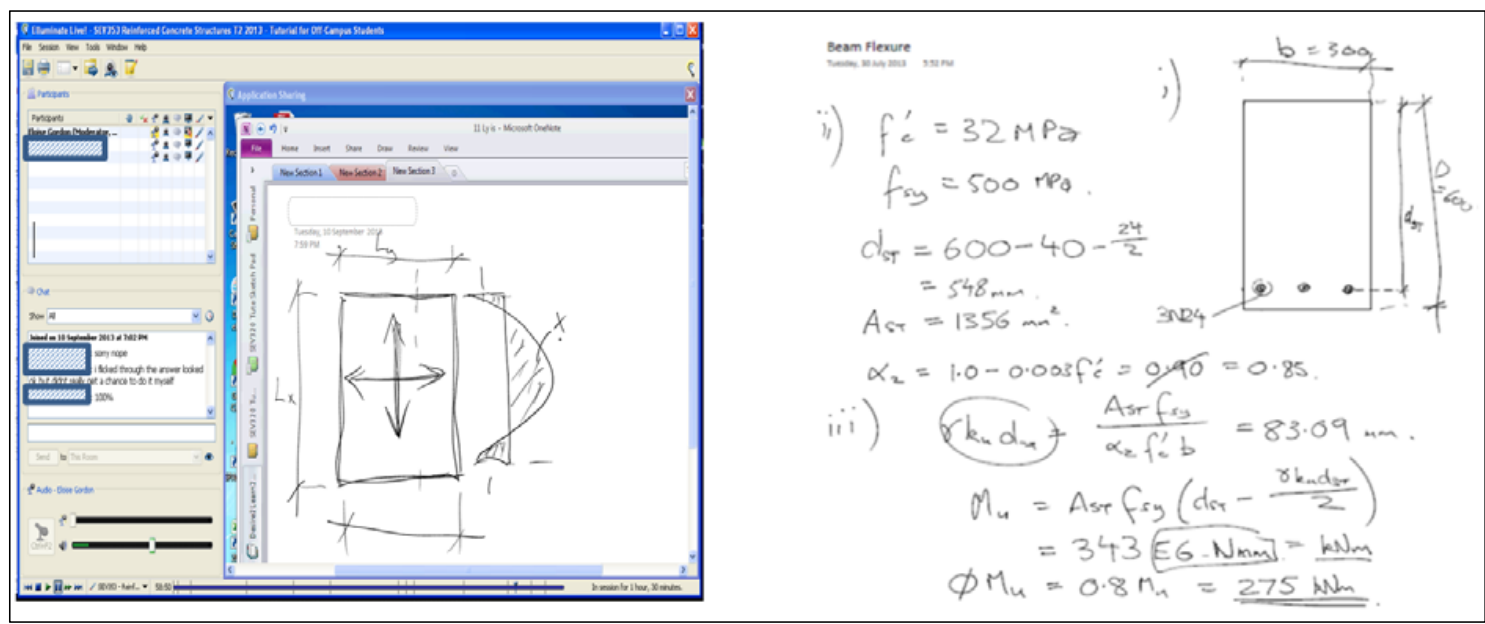

Figure 3: Screen-shot of E-live being used in a civil-engineering tutorial. The lecturer used a tablet-PC and shared One-Note software to write and present the solution to a problem.

The located learning environment and synchronous learning modes are often difficult to replicate for distance-based learning when demonstrating expensive commercial software applications and/or version-sensitive software applications such as CAD applications (e.g., SolidWorks, AutoCAD), project management applications (e.g., MS Project), and modelling applications (e.g., Abaqus) that are typically encountered in undergraduate engineering education. E-live enables the teaching and demonstration of such software applications in a multimode manner since the tutor can share with students the application user interface as it appears on the tutor's local host computer. If installed and available on the student's local host computer then students can also operate the software "hands-on" while the on-line tutorial occurs in real time (synchronous mode) or while accessing the tutorial recording (asynchronous mode).

A common problem for distance-based learning involving these types of software applications is the difficulty is distributing the software to students, wherever they may physically be, for them to install on their local host computers. Recently we have introduced the use of a remotedesktop service so that these types of software applications can be accessed by all students without the need for the applications to be installed and available on their local host computers. This provides a number of benefits:

- Better assurance that the software being demonstrated by the tutor is the same as used by all students especially if the tutor also uses the applications via the remote desktop service;

- Elimination of the need to distribute physical media to students for local installation of applications; 
- Product and version control of software applications available and used for learning and teaching purposes.

\section{student evaluations of on-line courses}

At the end of each semester, students are asked to fill in a questionnaire on how well the unit was delivered and taught. The questions are a series of statements on teaching, text materials, effectiveness of communication with the lecturer, library resources, relative difficulty, assessment tasks, and feedback on performance. The students indicate how much they agree with the statement by giving a number on a standard Lickert ${ }^{16}$ five-point scale where the number one is strongly disagree, three is neither agree nor disagree, and five is strongly agree. For this work we have selected one item for comparing student satisfaction: "The on-line teaching and resources in this unit enhanced my learning experience." Comparisons of answers to this question were made for all engineering subjects in 2012 and 2013. Three semesters run each year. Semester three is over the summer months, where a small number of engineering courses are offered. On the questionnaires, students are also allowed to make written comments.

\section{results}

Figure 4 shows the average scores from student evaluations of on-line courses across the School of Engineering for the years 2012 and 2013. In 2012 most, but not all, courses ran E-live classes for on-line students. Beginning in semester two 2013, all engineering subjects ran E-live classes for on-line students.

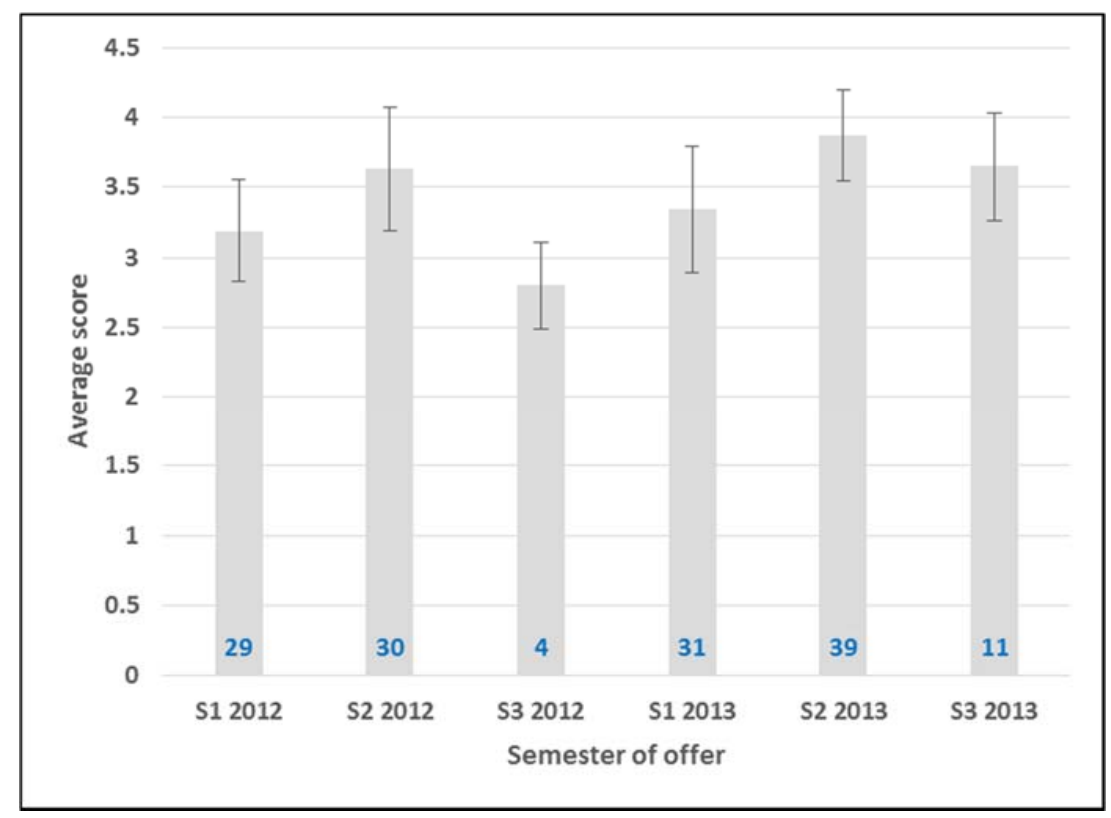

Figure 4: Average student evaluation scores to the statement: "The on-line teaching and resources in this unit enhanced my learning experience," for all on-line engineering courses taught in 2012 and 2013. The number at the bottom of each column is the number of on-line courses offered in that semester. 
Beginning in semester two 2013, all engineering subjects ran E-live classes for on-line students. Meaningful comparisons can only be made for similar semesters, as the precise courses offered varies from semester to semester, but not, in general, from one year to the next. The data do show an increase in student satisfaction in on-line teaching from 2012 to 2013, but not necessarily from one semester to the next. An overall look at all the questions in the student evaluations across engineering indicate that students in semester three 2013 were much more satisfied with the delivery of on-line subjects than they were in semester three 2012.

Written comments from students (table 1) also reflected this sentiment. While the use of E-live is only one of many factors in a student's experience of an on-line course, we believe that it is a significant one.

Table 1: Some Student Comments from the Course Evaluations

\begin{tabular}{|l|l|}
\hline Subject & Student comment \\
\hline 3rd-year Control theory & $\begin{array}{l}\text { Elive tutorials are ABSOLUTELY ESSENTIAL for this unit to be of } \\
\text { any value to the understanding of the theory involved. }\end{array}$ \\
\hline $\begin{array}{l}3^{\text {rd }} \text {-year Concrete } \\
\text { Structures }\end{array}$ & Elive tutorials for off campus students were extremely helpful. \\
\hline $\begin{array}{l}3^{\text {rd }} \text {-year Project } \\
\text { Management }\end{array}$ & $\begin{array}{l}\text { (The best part of the subject was...) the elives that Simon conducted } \\
\text { for off-campus students. }\end{array}$ \\
\hline $\begin{array}{l}1^{\text {st }} \text {-year Electrical } \\
\text { Systems }\end{array}$ & (The best part of the subject was...) elives and pracs. \\
\hline $\begin{array}{l}4^{\text {th}} \text {-year Advanced Stress } \\
\text { Analysis }\end{array}$ & $\begin{array}{l}\text { (The best part of the subject was the tutor...) being willing to put on } \\
\text { extra elives to assist us and how he continued to try to learn the } \\
\text { software. }\end{array}$ \\
\hline $\begin{array}{l}2^{\text {nd }} \text {-year Materials } \\
\text { (The tutor) provided weekly elive tutorials for the on campus students } \\
\text { explaining on the required calculations and also an idea of what to } \\
\text { expect from certain materials/processes/treatments. }\end{array}$ \\
\hline $\begin{array}{l}2^{\text {nd }} \text { year Fluid Mechanics } \\
\text { Elive tutorials were good, and (the lecturer) should be commended for } \\
\text { initiating this. }\end{array}$ \\
\hline $1^{\text {st }- \text {-year Physics }}$ & (The tutor) was very helpful on the eLive Tutes. \\
\hline $1^{\text {st }- \text { year Physics }}$ & The elive prac's were very good. \\
\hline $1^{\text {st-year Physics }}$ & Elive tutorials ..., I would have been lost without these. \\
\hline $\begin{array}{l}3^{\text {rd }} \text {-year Theory of } \\
\text { Structures }\end{array}$ & $\begin{array}{l}\text { (The lecturer) was very accommodating with the eLive tutorial } \\
\text { sessions, providing flexibility of times and explaining things very well } \\
\text { in the tutorials. }\end{array}$ \\
\hline $4^{\text {th }}$-year Materials & Real time online tutorials. They were as good as face to face tutorials. \\
\hline
\end{tabular}

\section{discussion}

For on-line, off-campus students, an observed benefit of on-line tutorial classes conducted using the web-conferencing method was the peer-based social learning environment it enabled, as is often sought in campus-based classes. It was observed that students often assisted each other during the on-line tutorials - not only with the intended learning objectives for the session but also with ad-hoc matters such as configuring their computer for web-conferencing and reinforcing advice and guidance provided by the tutor. It was directly observed that students participating in the on-line classes were more likely to participate on an un-prompted basis as 
compared to the common environment of the campus based class for this type of computerintensive tutorial.

The authors believe that the E-live software has been valuable in facilitating meaningful interactions that have added value to the learning experiences of engineering students. Looking forward, we aim to encourage more student-produced content and interaction. As students become better equipped with their own Tablet PCs, we plan to facilitate the production and sharing of individual and small group student solutions in these E-live tutorials, via the use of other functions such as "breakout rooms."

In this short study, we have demonstrated the benefits of offering real-time, web-conferencing classes to on-line students in engineering. Our next step is to perform a more detailed analysis of course-evaluation data to see if deeper correlations exist between student feedback and these E-live tutorials. Also, we plan to send questionaires to participating students to obtain their views specifically about $E$-live classes and how they may be improved.

\section{conclusion}

Real-time, on-line engineering classes have been provided across the Deakin University School of Engineering by means of the web-conferencing software Elluminate-Live! Starting with one or two subjects in 2009, its use has grown to being applied across all courses in the School from semester two 2013. On-line, off-campus students have received these classes well, and the overall student satisfaction with the on-line learning environment has increased over the two years 2012-2013. We believe that real-time web-conferencing can be applied in many engineering schools to enhance teaching and communication, reduce pressure on campus facilities, and enhance the educational experience of on-line students.

\section{references}

1. Anastasiadis, P., and Metaxas, G. (2006). "Issues of importance in engineering education and distance learning," World Transactions on Engineering and Technology Education, 5(3), 393-396.

2. Cleveland-Innes, M.F., and Garrison, D.R. editors (2010). An Introduction to Distance Education: Understanding Teaching and Learning in a New Era (New York: Routledge).

3. Bourne, J., Harris, D., and Mayadas, F. (2005). "Online Engineering Education: Learning Anywhere, Anytime,” Journal of Engineering Education 94(1), 131-146.

4. Dickrell, D. (2012). "Applying Distance Education Technologies to a Large-Scale Engineering Mechanics Course," $119^{\text {th }}$ American Society for Engineering Education Annual Conference Proceedings (San Antonio), session T518.

5. Krute, L. (2012). "Distance Education Partnerships," $119^{\text {th }}$ American Society for Engineering Education Annual Conference Proceedings, session M614.

6. Long, J.M., Joordens, M.A. and Littlefair, G. (2014). “Engineering Distance Education At Deakin University Australia," to be presented at the IACEE 14th World Conference for Continuing Engineering Education, Stanford University, 24-27 June.

7. Palmer, S, and Bray, S.L (2002). "On- and off-campus Student Persistence and Academic Performance,” Engineering Science and Education Journal 11(2), 66-72. 
8. Long, J.M. and Baskaran, K. (2004). "Engineering Education Down Under: Distance Teaching at Deakin University, Australia,” 2004 Annual Conference of the American Society for Engineering Education Proceedings (Salt Lake City), session 2160.

9. Palmer, S, and Bray, S. (2005). "Assessing the likely impact of mandatory residential sessions for engineering and technology students," in Proceedings of the 2005 ASEE/AaeE 4th Global Colloquium on Engineering Education (Sydney), 26-30 September, Australasian Association for Engineering Education.

10. Gordon, E., Joordens, M., Stojcevski, A. (2013). "Effective technology to support cooperative learning in a virtual learning environment," Proceedings of the 2013 Australasian Association for Engineering Education Conference, editors C. Lemckert, G. Jenkins, and S. Lang-Lemckert (Gold Coast, Australia), 8-11 December.

11. Long, J.M., Chenery, K.L., Stannard, W.B., and Fitzgerald, K.J. (2013). "Use of web-Conferencing Software to Enhance Practical Learning for Distance Students in a First-year Engineering Course," Proceedings of the 2013 Australasian Association for Engineering Education Conference, editors C. Lemckert, G. Jenkins, and S. Lang-Lemckert (Gold Coast, Australia), 8-11 December.

12. Elluminate Live!, (2009). "The Impact of Synchronous Online Learning on Academic Institutions: Customer Experiences from K-12 and Higher Education”, white paper, see

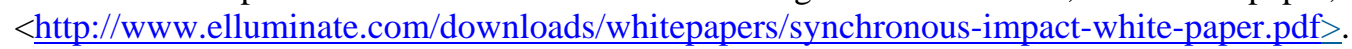

13. Chaturvedi, S, Prabhakaran, R, Yoon, J \& Abdel-Salam, T (2011). "Engineering Laboratory Instruction in Virtual Environment - eLIVE”, Advances in Engineering Education, vol. 2, no. 4, 1-24.

14. Page, GA, Pauli, JT, Sturm, C \& Fierstein, M (2011). "Faculty Adoption of Technology: The Case of Elluminate," Proceedings of the Society for Information Technology and Teacher Education International Conference, editors M. Koehler and P. Mishra, pp. 606-614, $<\underline{\text { http://www.editlib.org/p/36339>. }}$.

15. Behling, K.R., Orczyk, J.J., and Jenkins, L.J. (2007). "Live Distance Learning Delivery of Master of Science Courses in Building Construction Management," Proceedings of the $37^{\text {th }}$ ASEE/IEEE Frontiers in Education Conference (Milwaukee), 10-13 October, session F3D-9.

16. Wiersma, W., and Jurs, S.G. (2009). Research Methods in Education: an Introduction, $9^{\text {th }}$ edition (Boston: Pearson/Allyn and Bacon). 